\title{
Proximity of the poly(A)-binding protein to a premature termination codon inhibits mammalian nonsense-mediated mRNA decay
}

\author{
ANA LUÍSA SILVA, ${ }^{1}$ PATRÍCIA RIBEIRO, ${ }^{1}$ ÂNGELA INÁCIO, ${ }^{1}$ STEPHEN A. LIEBHABER, ${ }^{2}$ and LUÍSA ROMÃO ${ }^{1}$ \\ ${ }^{1}$ Centro de Genética Humana, Instituto Nacional de Saúde Dr. Ricardo Jorge, 1649-016 Lisboa, Portugal \\ ${ }^{2}$ Departments of Genetics and Medicine, University of Pennsylvania, Philadelphia, Pennsylvania 19104, USA
}

\begin{abstract}
mRNA surveillance pathways selectively clear defective mRNAs from the cell. As such, these pathways serve as important modifiers of genetic disorders. Nonsense-mediated decay (NMD), the most intensively studied surveillance pathway, recognizes mRNAs with premature termination codons (PTCs). In mammalian systems the location of a PTC more than 50 nucleotides $5^{\prime}$ to the terminal exon-exon junction is a critical determinant of NMD. However, mRNAs with nonsense codons that fulfill this requirement but are located very early in the open reading frame can effectively evade NMD. The unexpected resistance of such mRNAs with AUG-proximal PTCs to accelerated decay suggests that important determinants of NMD remain to be identified. Here, we report that an NMD-sensitive mRNA can be stabilized by artificially tethering the cytoplasmic poly(A) binding protein 1, PABPC1, at a PTC-proximal position. Remarkably, the data further suggest that NMD of an mRNA with an AUG-proximal PTC can also be repressed by PABPC1, which might be brought into proximity with the PTC during cap-dependent translation and 435 scanning. These results reveal a novel parameter of NMD in mammalian cells that can account for the stability of mRNAs with AUG-proximal PTCs. These findings serve to expand current mechanistic models of NMD and mRNA translation.
\end{abstract}

Keywords: mammalian nonsense-mediated mRNA decay (NMD); 50-54 nt boundary rule; short open reading frame (ORF); poly(A)-binding protein; translation

\section{INTRODUCTION}

Nonsense-mediated mRNA decay (NMD) is an mRNA surveillance mechanism that rapidly degrades mRNAs carrying premature translation termination codons (PTCs). In mammalian cells, NMD depends on the interaction of the termination complex with a multi-component exonjunction complex (EJC) (for review, see Chang et al. 2007). The EJC is deposited 20-24 nucleotides (nt) upstream of each exon-exon junction during splicing (Le Hir et al. 2001). According to the present model for mammalian NMD, the EJC, or a critical subset of EJC components, remains associated with the mRNA during its transport to the cytoplasm. Translating ribosomes subsequently displace EJCs from the open reading frame (ORF) during the initial

Reprint requests to: Luísa Romão, Centro de Genética Humana, Instituto Nacional de Saúde Dr. Ricardo Jorge, Av. Padre Cruz, 1649016 Lisboa, Portugal; e-mail: luisa.romao@insa.min-saude.pt; fax: (+351) 217526410 .

Article published online ahead of print. Article and publication date are at http://www.rnajournal.org/cgi/doi/10.1261/rna.815108. ("pioneer") round of translation (Ishigaki et al. 2001; Lejeune et al. 2002). However, if an mRNA contains a PTC located more than 50-54 nt upstream of the last exonexon junction, the ribosome will fail to displace distal EJC(s). In this case, when the ribosome reaches the PTC, the translation release factors eRF1 and eRF3 at the PTC interact in cis with the retained EJC(s) via a multiprotein bridge (Kashima et al. 2006). Of central importance in this reaction is the interaction of UPF1 with the terminating complex and with the UPF2/UPF3 components of the retained EJC(s) (Kashima et al. 2006). This interaction marks the mRNA for rapid decay.

In contrast to the EJC-dependent mammalian NMD pathway, targeting of nonsense-containing mRNAs in lower eukaryotes appears to reflect distinct determinants. For example, NMD in the yeast Saccharomyces cerevisiae appears to be activated by an inappropriate sequence and/ or structure context of the PTC (Amrani et al. 2004) resulting in aberrant and inefficient ribosome release (Amrani et al. 2004). The resultant termination defect and associated NMD can be abolished by flanking the 
nonsense codon with a native $3^{\prime}$ untranslated region (UTR) or by tethering the poly(A)-binding protein downstream from a PTC to mimic a normal 3' terminus (Amrani et al. 2004, 2006). The position of nonsense codons relative to the cytoplasmic poly(A)-binding protein 1 (PABPC1) is also a critical determinant for PTC definition in Drosophila melanogaster (Behm-Ansmant et al. 2007). The existence of global differences among the mechanisms and pathways of NMD in yeast, Drosophila, and mammalian cells (Conti and Izaurralde 2005) raises the question of whether structural parameters of NMD such as context of the termination codon and proximity of the PABPC1 extend to mammalian systems. Furthermore, the resistance to NMD of mRNAs with PTCs located early in the ORF establishes an apparent exception to the EJC model (Romão et al. 2000; Inácio et al. 2004). Thus, the physical parameters and mechanistic pathway(s) that mediate NMD in mammalian organisms remain to be more fully defined. Here, we explore the effect of these parameters on the mammalian NMD mechanism and apply our findings to understanding the basis for NMD resistance of mRNAs with AUG-proximal PTCs.

\section{RESULTS}

We have previously reported that human $\beta$-globin mRNAs carrying $5^{\prime}$-proximal nonsense mutations evade NMD. This resistance to NMD does not reflect abnormal RNA splicing, translation reinitiation, or impaired translation (Romão et al. 2000; Inácio et al. 2004). Instead, the critical parameter for NMD resistance reflects the proximity of the nonsense codons to the translation initiation AUG (Inácio et al. 2004; Silva et al. 2006). This "AUGproximity effect" appears to constitute a general attribute of mammalian NMD that is independent of sequence context and independent of the 5' UTR length (Silva et al. 2006). These findings suggest that the observed NMD resistance may reflect specific attributes of an exceptionally early translation termination event.

\section{The AUG-proximal nonsense-mutated mRNPs are defective in UPF1}

To explore NMD resistance of mRNAs with AUG-proximal PTCs, we performed the comparative analysis of UPF factors association with normal $\beta$-globin mRNA $(\beta N)$, NMD-resistant mRNA containing an AUG-proximal nonsense mutation ( $\beta 15$; nonsense codon at position 15 ), and NMD-sensitive mRNA containing a more distal PTC ( $\beta 39$; nonsense codon at position 39) (Fig. 1A). HeLa cells were stably transfected with vectors containing the $\beta \mathrm{N}$, $\beta 15$, or $\beta 39$ globin genes and levels of $\beta$-globin mRNA were determined in the respective cell pools by semiquantitative RT-PCR. mRNA levels were normalized to the level of endogenous RNA polymerase II mRNA in each sample. Both RT-PCR amplimer sets encompassed at least one exon-exon junction to discriminate mRNA from DNA amplification. Consistent with prior studies (Romão et al. 2000 ), the level of the NMD-sensitive $\beta 39$ mRNA was markedly lower than the $\beta \mathrm{N}$ mRNA while the $\beta 15$ mRNA was expressed at levels equivalent to the $\beta \mathrm{N}$. These data reflected the NMD sensitivity of the $\beta 39$ and the NMD resistance of the $\beta 15$ mRNAs (Fig. 1C, lanes 1-3). Lysates of each cell pool were also prepared and analyzed by Western blot with antibodies anti-UPF1, -UPF2, and -UPF3b (Fig. 1B, lanes 1-3). Relative to Pre-IP, 10-fold more of each of the three transfected cell pools were lysed and separately immunoprecipitated (IP) with antibodies against UPF1, UPF2, and UPF3b. To confirm specificity of each antibody, lysates from HeLa cells stably transfected with $\beta \mathrm{N}$ were immunoprecipitated with a nonspecific (NS) antibody; then, all IP samples were analyzed by Western blot, using each of the corresponding anti-UPF antibodies. As shown in Figure 1B, each of the UPF proteins is mainly detected in the corresponding IP when compared to the control IP carried out with the NS antibody (Fig. 1B, cf. lanes 1-6 and lane 7). The levels of $\beta$-globin mRNA copurified in each immunoprecipitation sample were compared to the content of RNA polymerase II mRNA in the same IP. This was done to normalize for the different affinities and IP efficiencies that are intrinsic to each of the UPF antisera. RNA polymerase II transcripts have introns and are thus subject to splicing and EJC deposition and should retain EJC components, such as UPF factors, until removed by the pioneer round of translation. Each normalized value was compared to that of $\beta \mathrm{N}$ mRNA (defined as 1.0; relative mRNA levels). A two-tailed Student's $t$-test comparison of the $\beta 15$ or $\beta 39$ relative mRNA levels before and after IP (Fig. 1D) confirmed that, even assuming a heteroskedastic variance (unequal variance) within the data set, only the coimmunoprecipitation of $\beta 15$ mRNA with UPF1 protein presents a nonsignificant difference $(P>$ 0.05 ) between Pre-IP and IP values, relative to the corresponding normal control (Fig. 1D). An enrichment ratio of each mRNA was calculated by dividing the relative mRNA levels in the IP by those in the corresponding starting Pre-IP (Fig. 1E; "IP enrichment ratios": an enrichment equivalent to that of $\beta \mathrm{N}$ mRNA corresponds to 1.0). The IP enrichment ratios for the $\beta 15$ and $\beta 39$ mRNAs (Fig. 1E) revealed that the $\beta 15$ and $\beta 39$ mRNAs are both threefold enriched relative to $\beta \mathrm{N}$ mRNA for the EJCintrinsic UPF3b protein and twofold enriched for the EJC associated UPF2 protein. In contrast, the analysis of the UPF1 immunoprecipitations revealed a selective 2.5-fold enrichment for $\beta 39$ mRNA and no UPF1 enrichment for the $\beta 15$ mRNA (Fig. 1E). A two-tailed Student $t$-test comparison of the $\beta 15$ and $\beta 39$ IP enrichment ratios in the three immunoprecipitations (Fig. 1E), confirmed that the corresponding UPF1 co-IP values are significantly different $(P<0.05)$. These data indicate that $\beta 15$ and $\beta 39$ mRNAs both retain the UPF2- and UPF3b-EJC components, which 
A

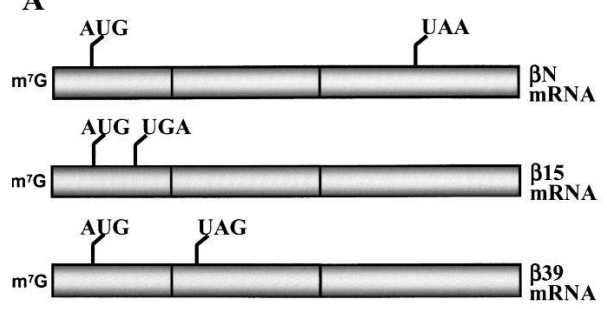

B

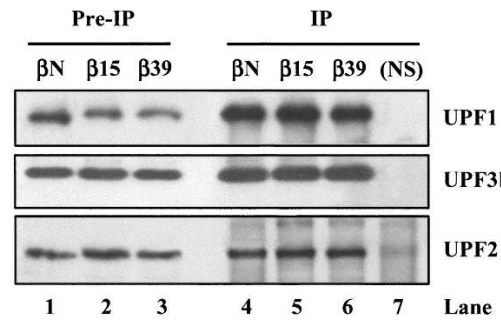

C

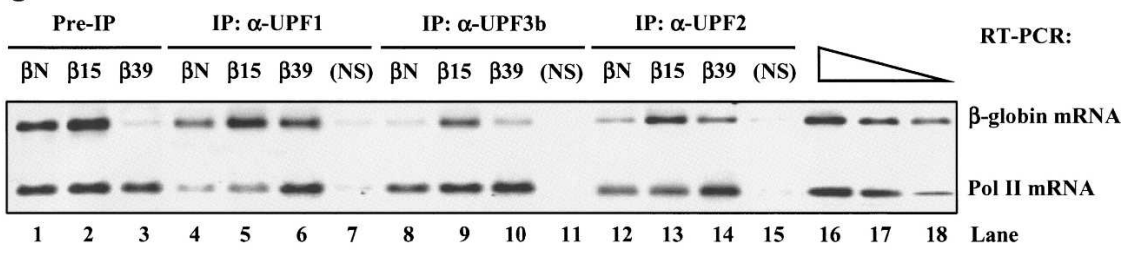

D

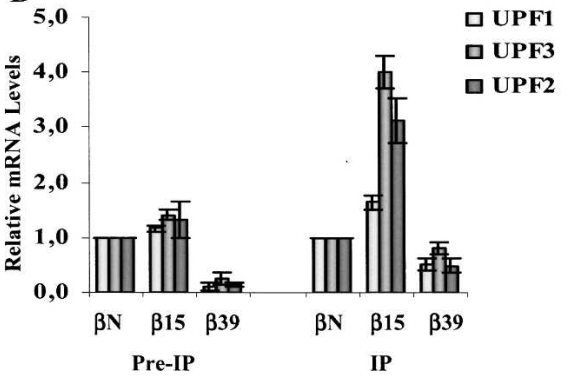

$\mathbf{E}$

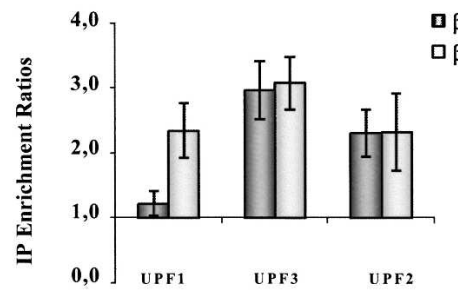

is in accordance with the fact that both transcripts carry a nonsense mutation that is located farther than 50-54 nt upstream of the last exon-exon junction of the transcript. Furthermore, taking into account that the PTC on $\beta 15$ mRNA is located less than $50 \mathrm{nt}$ upstream of the first exon-exon junction and considering the sizes of the ribosome and the EJC, one would predict that the terminating ribosome at $\beta 15$ PTC would impact on the first EJC, possibly displacing it, which is consistent with the comparable amounts of UPF2 and UPF3b present in $\beta 15$ and $\beta 39$ mRNP co-IPs. The relative lack of EJCs on the normal $\beta \mathrm{N}$ transcripts is consistent with their removal during the first round of translation. Finally, the data reveal that $\beta 39 \mathrm{mRNP}$ is enriched with UPF1 when compared with $\beta \mathrm{N}$ mRNP, while the association of $\beta 15$ mRNA with UPF1 is comparable to the $\beta N$ control. This could either reflect a defect in the ability of the $\beta 15$ mRNA to recruit UPF1 or an increased dissociation of this factor from the $\beta 15$ mRNP, which may both correlate with its resistance to NMD. Although UPF1 is considered the central player for NMD triggering among the several organisms analyzed so far, it remains to be clarified whether a premature termination event is a requisite for UPF1 recruitment. Actually, the first direct biochemical evidence for UPF1 association with the termination complex in mammals was provided by Kashima et al. (2006). Here the authors showed that UPF1, SMG-1, eRF1, and eRF3 can form a complex (which they called SURF), and that the formation of SURF is UPF2-EJC independent, supporting the idea that the interaction between UPF1 and the translation termination complex occurs prior to the interaction of UPF1 with the EJC. Thus, this raises the possibility that UPF1 might be recruited to the translation termination complex, whether this event is premature or not, and that the following events involving the interplay between UPF1 and EJC would contribute to PTC definition. This interplay 
could also contribute to sustain the association of UPF1 with the mRNP.

\section{Tethering cytoplasmic poly(A)-binding protein 1 (PABPC1) at a position 15 codons downstream from a PTC can stabilize an NMD-sensitive mRNA}

The cytoplasmic poly(A) binding protein 1, PABPC1, can bind simultaneously to the cap-associated eIF4G and to the poly(A) tail (Wells et al. 1998). This dual binding has the potential to bridge the $3^{\prime}$ and $5^{\prime}$ termini of an mRNA resulting in a circularized or "closed loop" conformation (Wells et al. 1998). This closed loop brings the PABPC1 into close proximity with $5^{\prime}$ structures in the mRNA. Furthermore, in cap-dependent translation, eIF4G and associated factors are likely to maintain the interaction with 43S subunit throughout ribosome scanning (Poyry et al. 2004; Jackson 2005). The continued interaction between eIF4G and the $43 \mathrm{~S}$ subunit could also have the potential to bring the associated PABPC1 to the AUG. In this regard it is interesting to note that our prior studies of AUGproximal PTCs demonstrate that these NMD-resistant transcripts become NMD competent when the distance between the PTC and the AUG is increased but not when the 5'UTR length is increased by the same extent (Inácio et al. 2004; Silva et al. 2006). Hypothesizing that PABPC1 and associated factors might be brought into the vicinity of the AUG via the cap-dependent translation, the mechanism for this conversion to NMD sensitivity may relate to the increase in distance between the $5^{\prime}$ associated PABPC1 and the PTC.

The relationship between PABPC1 and NMD was tested by artificially tethering PABPC1 in close proximity to an NMD-sensitive PTC. A 24 basepair (bp) MS2 coat protein-binding site was inserted at a position 15 codons downstream from the $\beta 39$ PTC (Fig. $2 \mathrm{~A})$. The corresponding mRNA was expressed in HeLa cells in the presence of one of four coexpressed proteins:
A

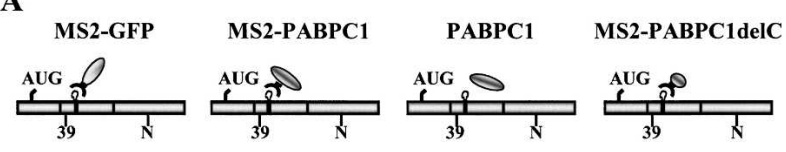

B

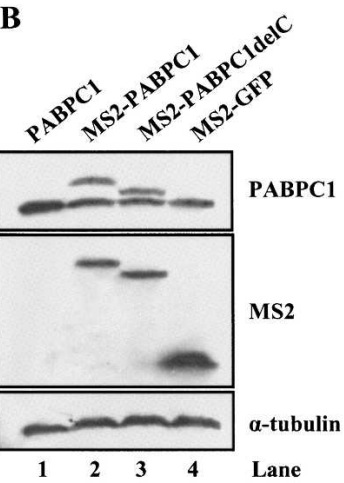

C
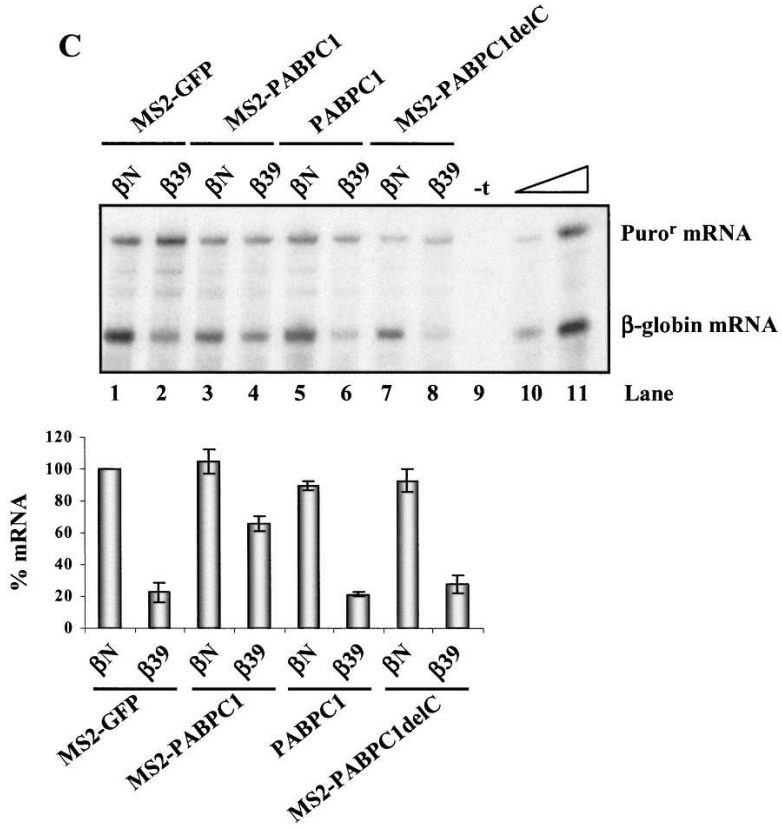

D
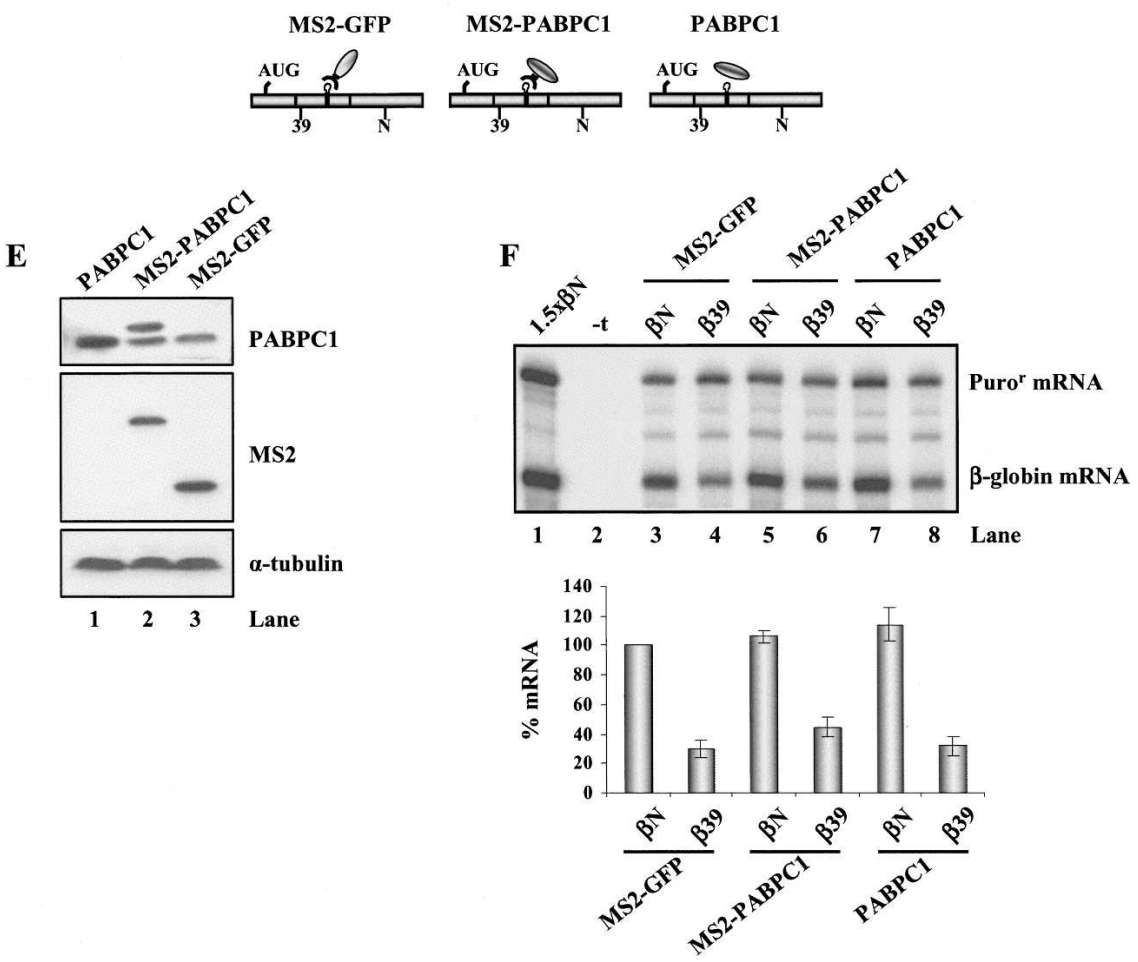

FIGURE 2. (Legend on next page) 
MS2-GFP, MS2-PABPC1, PABPC1, or MS2-PABPC1 lacking its C-terminal domain (Fig. 2A, MS2-PABPC1delC). The C-terminal region of PABPC1 that is removed in the PABPC1delC protein is known to interact with a number of proteins, including eRF3 (Hoshino et al. 1999). Levels of expression of each protein were monitored by Western blot (Fig. 2B), and levels of the $\beta$-globin mRNA were quantified by RNase protection assays (RPA) (Fig. 2C; see Materials and Methods). The level of $\beta N$ mRNA cotransfected with the MS2-GFP protein was set as $100 \%$ and $\beta$-globin mRNA levels in all cotransfections were normalized to that value. The levels of normal controls in each cotransfection were similar to the one of $\beta N$ mRNA when cotransfected with the MS2-GFP protein (Fig. 2C, cf. lanes 3,5,7 and lane 1), indicating that $\beta \mathrm{N}$ mRNA levels were not affected by the various coexpressed proteins. The levels of the $\beta 39 \mathrm{mRNA}$ remained quite low when cotransfected with the MS2-GFP protein (23\% of $\beta \mathrm{N}$ mRNA) (Fig. 2C, cf. lane 2 and lane 1). In marked contrast, coexpression of MS2-PABPC1 increases the level of $\beta 39$ mRNA to $66 \%$ of normal (Fig. $2 \mathrm{C}$, cf. lane 4 and lane 1$)$. This stabilizing effect on $\beta 39$ mRNA was not observed by coexpressing the untethered

FIGURE 2. Proximity of PABPC1 to a nonsense codon blocks NMD in mammalian cells. $(A)$ Schematic representation of the reporter $\beta 39$ mRNA carrying the MS2 coat protein-binding site (represented by a loop) inserted at 15 codons downstream from the $\beta 39$ PTC. The mRNA is shown in the presence of each of four coexpressed proteins: MS2-GFP, MS2-PABPC1, PABPC1, or MS2-PABPC1delC. The predicted tethering, or lack of tethering, is indicated. $(B)$ Western blot using anti-PABPC1, anti-MS2, or anti- $\alpha$-tubulin antibodies to show expression levels of each of the four coexpressed proteins. The anti- $\alpha$-tubulin served as a control for variations in protein loading. $(C)$ Tethering PABPC1 15 codons $3^{\prime}$ to the PTC on $\beta 39$ mRNA represses NMD. HeLa cells were cotransfected with the plasmids carrying the $\beta$-globin-MS2 reporters indicated above each lane (plasmids also contain the puromycin resistance [Puro ${ }^{\mathrm{r}}$ ] gene) and plasmids encoding the MS2-GFP (lanes 1,2), MS2-PABPC1 (lanes 3,4), MS2PABPC1 with its C-terminal domain deleted (PABPC1delC; lanes 7,8), or untagged PABPC1 (lanes 5,6), as indicated. $\beta$-globin-MS2 mRNA levels were analyzed by RPA and quantified relatively to the Puro ${ }^{\mathrm{r}}$ mRNA. Lanes 10 and 11 (wedge), contain a 0.5 - and 1.5 -fold (relative to lane 1) of the amount of input mRNA from HeLa cells transfected with the $\beta \mathrm{N}$ gene, respectively, to show that the experimental RPA was carried out in conditions of probe excess. RNA isolated from a nontransfected $(-t)$ HeLa control is shown in lane 9. The histogram shown below the autoradiograph compares levels of $\beta 39$ mRNAs in each set of cotransfections relative to $\beta \mathrm{N}$ mRNA expression in the presence of MS2-GFP tethered protein (defined as $100 \%)$. Each bar is aligned to the corresponding lane in the autoradiograph and represents the mean and standard deviation of four independent experiments corresponding to four independent transfections. (D) Schematic representation of the reporter mRNAs carrying the MS2 coat protein binding site (represented by a loop) inserted at 44 codons downstream from the stop codon. Above, reporter mRNAs is represented each fusion protein or the wildtype PABPC1 protein. (E) Western blot using anti-PABPC1, anti-MS2, or anti- $\alpha$-tubulin antibodies to show expression levels of the tethered proteins at 44 codons downstream from the codon 39 or the wild-type PABPC1 protein. The anti- $\alpha$-tubulin served as a control for variations in protein loading. $(F)$ Tethering PABPC1 44 codons $3^{\prime}$ to the PTC on $\beta 39$ mRNA does not appreciably repress NMD. HeLa cells were cotransfected with the plasmids carrying the $\beta$-globin-MS2 reporters indicated above each lane and plasmids encoding the MS2-GFP (lanes 3,4), MS2-PABPC1 (lanes 5,6), or untagged PABPC1 (lanes 7,8), as indicated. $\beta$-globinMS2 mRNA levels were analyzed by RNase protection assays as in $C$. Lane 1 contains 1.5 -fold more input mRNA from HeLa cells transfected with $\beta N$ gene than in the remaining samples, which demonstrates that probes were used in excess and the experiment was quantitative. The histogram shown below the autoradiograph compares levels of $\beta 39$ mRNAs in each set of cotransfections relative to $\beta \mathrm{N}$ mRNA expression in the presence of MS2-GFP protein (defined as $100 \%)$. Each bar represents the mean and standard deviation of three independent experiments, each one performed with RNA from independent transfections.
PABPC1 (levels remain at about $21 \%$ of normal) (Fig. 2C, 6) or the PABPC1delC protein (levels remain at about tethering of PABPC 15 codons $3^{\prime}$ of a PTC can stabilize an NMD-sensitive mRNA in human cells. In addition, this stabilization effect appears to be dependent on the protein interactions occurring with the C-terminal domain of

To confirm that the observed stabilization effect of the tethered PABPC1 depends on its proximity to the PTC, the same MS2 coat protein-binding site was inserted at 4 codons downstream from the $\beta 39$ PTC (Fig. 2D). These genes were expressed in HeLa cells in the presence of MS2Wester the $\beta$-globin mRNA were quantified by RPA (Fig. $2 \mathrm{~F}$ ). As in the prior study, expression of MS2-PABPC1 and PABPC1 proteins had no effect on the $\beta \mathrm{N}$ mRNA levels (Fig. 2F, 5,7 and lane 3). In addition, tethering the control coexpressing the nontethered PABPC1 had no effect on $\beta 39$ mRNA levels (levels at $32 \%$ of $\beta N$ ) (Fig. 2F, lanes 4,8).

Tethering the MS2-PABPC1 appeared to result in a slight increase of the level of $\beta 39$ mRNA ( $45 \%$ of $\beta \mathrm{N}$ ) (Fig. $2 \mathrm{~F}$, lane 6). This effect is half of that obtained by tethering the same protein 15 codons downstream of the PTC (1.5-fold versus 3 -fold). Thus, the tethering of PABPC1 at 15 codons downstream from the PTC suppressed NMD, while, for unknown reasons, tethering PABPC1 further $3^{\prime}$, at 44 codons, had no considerable NMD repression effect. Although these data are consistent with the effect exerted by PABPC1 on NMD suppression being dependent on its proximity to the PTC, further studies are required to firmly establish this relationship.

\section{An AUG-proximal nonsense-mutated mRNA is converted from NMD resistant to NMD sensitive when translation is independent of the elF4F complex and $43 S$ scanning}

The preceding study reveals that an artificially tethered PABPC1 can inhibit NMD when it is brought into close proximity to the PTC. Based on these results we considered the possibility that the NMD resistance of an AUG-proximal PTC might reflect the recruitment of PABPC1 to the $5^{\prime}$ end of the mRNA 
via PABPC1/eIF4G interactions (Wells et al. 1998). Since NMD resistance of the $\beta 15 \mathrm{mRNA}$ reflects the distance of a PTC from the 5' AUG rather than from the 5' cap (Inácio et al. 2004; Silva et al. 2006), this model further suggests that the proximity of the PABPC1 to the PTC reflects the distance of the PTC to the AUG initiation codon. These observations would be consistent with a model in which PABPC1 is bound to the eIF4G and remains associated with $43 \mathrm{~S}$ complex during scanning to the AUG. Such a model would predict that the $\beta 15$ mRNA, which is normally NMD resistant, would become NMD sensitive if translation initiation is mediated independently of eIF4G and $43 \mathrm{~S}$ scanning. To test this prediction we replaced the $5^{\prime}$ UTR of the $\beta$-globin mRNA with a $5^{\prime}$ UTR containing the classical swine fever virus (CSFV) IRES (for review, see Jackson 2005) (see Materials and Methods). This IRES is a hepatitis $\mathrm{C}$ virus (HCV)-like IRES that shares with it a similar length and a related structure (Pestova et al. 1998, and references therein). This category of IRESs binds 40S subunits directly, in the absence of the eIF4 initiation factor complex, and places the ribosomal $\mathrm{P}$ site in the immediate proximity of the initiation codon prior to direct $80 \mathrm{~S}$ assembly (Reynolds et al. 1996; Rijnbrand et al. 1997; Pestova et al. 1998). Based on these data, we expressed the $\beta N, \beta 15$, and $\beta 39$ mRNAs with their native $5^{\prime}$ UTR or with a substituted CSFV IRES (Fig. 3A, lanes 1-3,4-6, respectively) and assessed levels of mRNA in each case. Consistent with its reported resistance to NMD (Romão et al. 2000), the native $\beta 15$ mRNA (i.e., with the native $5^{\prime}$ UTR) was expressed at levels equivalent to $\beta \mathrm{N}$ mRNA, while the native $\beta 39$ mRNA was expressed at markedly reduced levels $(28 \%$ of $\beta \mathrm{N})$ (Fig. 3A, cf. lanes 2,3 and lane 1). Under the conditions of our study, we observed that $\beta 39$-IRES mRNA levels were reproducibly reduced to $64 \%$ of $\beta N$-IRES. Remarkably, in this same experimental context, $\beta 15$-IRES mRNA levels were decreased to the same extent as for the $\beta 39$ mRNA ( $63 \%$ of $\beta N$ ) (Fig.
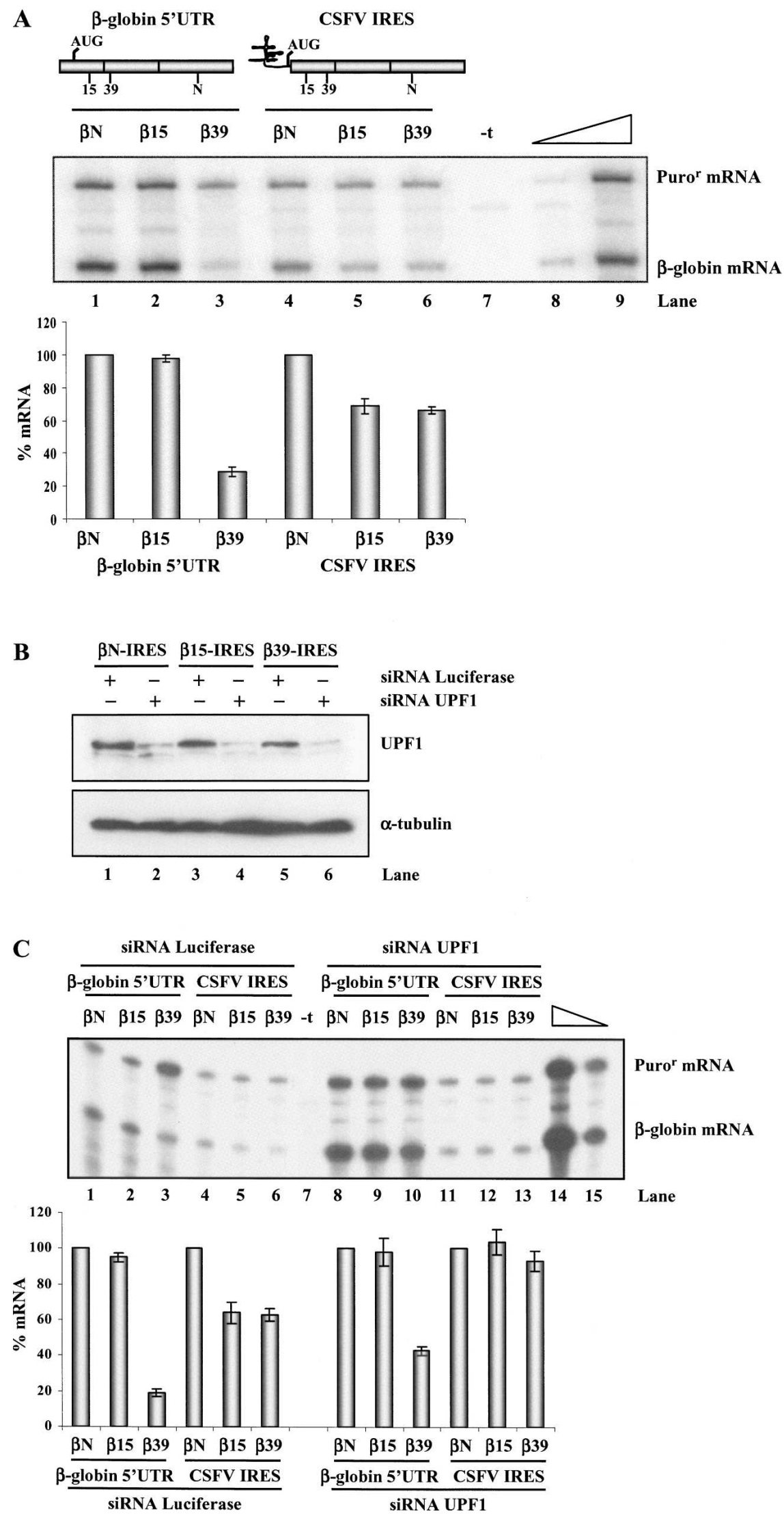

FIGURE 3. (Legend on next page) 
3A, cf. lanes 5,6 and lane 4). The fact that $\beta 15$ and $\beta 39$ transcripts did not reach low levels comparable to that observed for the native $\beta 39$ transcript (Fig. 3A, cf. lanes 5,6 and lane 3) probably reflects the relative inefficiency of the CSFV-IRES-mediated translation in HeLa cells (Holbrook et al. 2006). These data suggest that placing the $\beta 15$ mRNA under CSFV IRES translational control converts it from NMD resistant to NMD sensitive.

To confirm that the reduction of $\beta 15$-IRES and $\beta 39$ IRES mRNA was in fact mediated by NMD, the experiment was repeated in UPF1-depleted HeLa cells. UPF1 short interfering (si)RNA, or nonspecific control (Luciferase) siRNA, was cotransfected with each of the $\beta$-globin genes. Two days after transfection, a Western blot analysis demonstrated an $80 \%-90 \%$ decrease in UPF1 protein levels induced by siRNA (Fig. 3B, lanes 2,4,6), when compared with results obtained after treatment with the luciferase siRNA (Fig. 3B, lanes 1,3,5). The mRNA levels were quantified by RPA, relative to the normal controls expressed in the same conditions (Fig. 3C). Results show that in cells treated with the control siRNA (Luciferase siRNA), levels of the native $\beta$-globin mRNAs (Fig. 3C, lanes $1-3$ ) were concordant with results previously obtained in Figure 3A, and in both cases $\beta 15$ transcript is equivalent to $\beta \mathrm{N}$ while the NMD-sensitive $\beta 39$ is markedly decreased (19\% of $\beta N)$. Depletion of UPF1 resulted in a 2.4-fold increase of the abundance of the $\beta 39$ mRNA (Fig. 3C, lanes 10,3), consistent with an inhibition of the NMD pathway. Also, in agreement with the preceding experiment, the expression of the $\beta 15$-IRES and $\beta 39$-IRES mRNAs were both decreased relative to the $\beta N$-IRES mRNA in cells treated with luciferase siRNA (Fig. 3C; cf. lanes 5,6 and lane 4).
Remarkably, upon depletion of UPF1, the levels of the $\beta 39$ and $\beta 15$ mRNA linked to the CSFV IRES returned to normal (i.e., equivalent to $\beta N$-IRES mRNA levels) (Fig. 3C, cf. lanes 11-13 and lanes 4-6). The results of this full set of studies demonstrate that the AUG-proximal $\beta 15$ mRNA is converted from NMD resistant to NMD sensitive under conditions in which translation initiation is mediated independently of the eIF4F complex and $43 \mathrm{~S}$ scanning.

\section{Insertion of a pseudoknot structure into the ORF of an AUG-proximal nonsense-mutated mRNA converts it from NMD resistant to NMD sensitive}

A set of collected evidence supports that, after capdependent translation initiation, some initiation factors that were instrumental in promoting scanning-dependent initiation remain ribosome associated during translation of the initial codons (Kozak 2001; Poyry et al. 2004). Accordingly, data have been published showing that if the $5^{\prime}$-proximal AUG is followed by a short ORF, during translation termination the $40 \mathrm{~S}$ subunit can remain associated with the mRNA and resume scanning toward an AUG located downstream from the short ORF stop codon (Kozak 1987; Poyry et al. 2004). However, the efficiency of this event declines when the upstream ORF is lengthened or when the translation elongation is slowed within the short upstream ORF by a structural constraint. These data suggest that initiation factors required for scanning resumption are gradually lost in the course of elongation (Kozak 2001; Poyry et al. 2004). Based on this data, we hypothesized that the ORF length of the AUG-proximal nonsense-mutated $\beta$-globin transcripts may be too short to allow the initiation factors to dissociate in the course of elongation. This may favor the maintenance of PABPC1 and associated initiation factors near the AUG codon, while the short ORF is being translated and the ribosome reaches the PTC. This hypothesis was tested by slowing translation elongation across the ORF of an AUG-proximal nonsense-mutated $\beta$-globin transcript. To accomplish this, the first 19 codons of $\beta N, \beta 23$, or $\beta 39$ genes were replaced by a 19-codon sequence that forms a pseudoknot structure in the mRNA that has been shown to slow elongation (Kozak 2001) (see Materials and Methods). The human $\beta$-globin gene carrying a nonsense mutation at codon 23 ( $\beta 23)$ was used instead of the $\beta 15$ gene in these studies because the corresponding mRNA is also NMD resistant (Fig. $4 \mathrm{~A}$, cf. lane 2 and lane 1), and the ORF can accommodate the pseudoknot 
cassette without altering its overall length. The data in Figure 4A demonstrate that in transfected HeLa cells, the pseudoknot structure in the $\beta 39$ ORF has no substantial impact on NMD: the B39-pseudoknot transcript is expressed at approximately the same level as the native $\beta 39$ transcript (36\% and $29 \%$ of $\beta \mathrm{N}$ controls) (Fig. 4A, cf. lanes 3,6 and lanes 1,4 , respectively). As NMD is a translation dependent pathway, these results also demonstrate that the pseudoknot structure does not appear to affect overall translation efficiency, since $\beta 39$ mRNA remains fully committed to NMD. In contrast, when the pseudoknot sequence is inserted in the ORF of the $\beta 23$ mRNA, the level of mRNA decreases from $91 \%$ to about $62 \%$, relative to the corresponding normal controls (Fig. 4A, cf. lane 2 and lane 1, cf. lane 5 and lane 4). These results are consistent with the conclusion that the pseudoknot sequence converts the $\beta 23$ mRNA from NMD resistant to NMD sensitive. This effect is likely to be dependent on the pausing of translation induced by the pseudoknot structure rather than the particular sequence inserted, as our previous studies have shown that the NMD resistance of AUGproximal PTCs occurs in different transcripts and in different ORF sequence contexts (Silva et al. 2006).

To confirm that the decrease in $\beta 23$ mRNA reflects its conversion to NMD sensitivity, the study was repeated in cells depleted of UPF1 (Fig. 4B). UPF1 siRNA, or Luciferase siRNA, was cotransfected with each of the $\beta$-globin genes. Two days after transfection, a Western blot analysis showed a decrease of about $90 \%$ in UPF1 protein expression induced by siRNA (Fig. 4B, lanes $2,4,6$ ), when compared with results obtained after treatment with the luciferase siRNA (Fig. 4B, lanes 1,3,5). The mRNA levels were quantified by RPA, relative to the corresponding normal controls expressed in the same conditions (Fig. 4C). Results show that in cells treated with the control siRNA, levels of the native $\beta 23$ and $\beta 39$ mRNAs are at about $97 \%$ and $19 \%$ of the normal level (Fig. 4C, cf. lanes 2,3 and
A
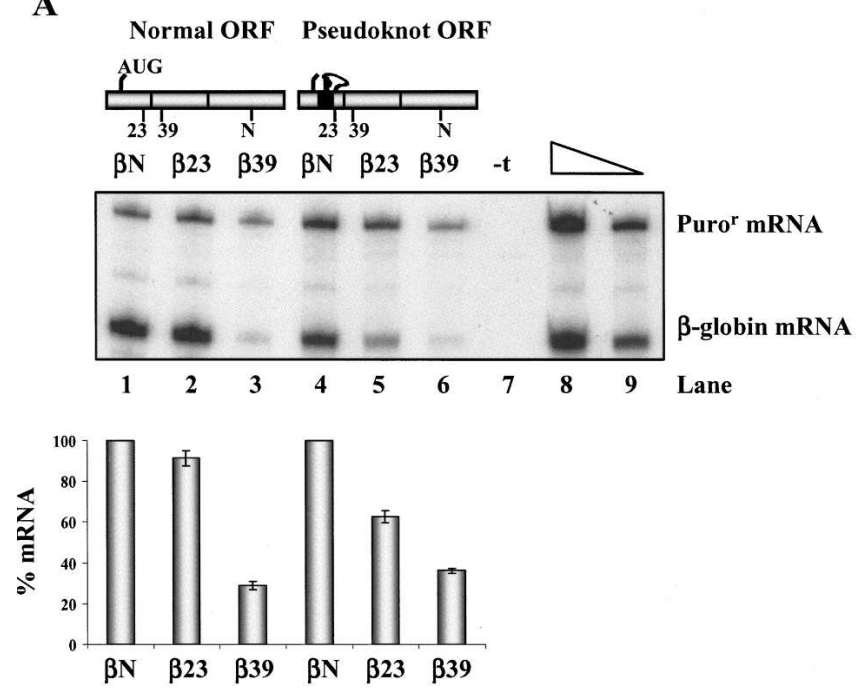

B

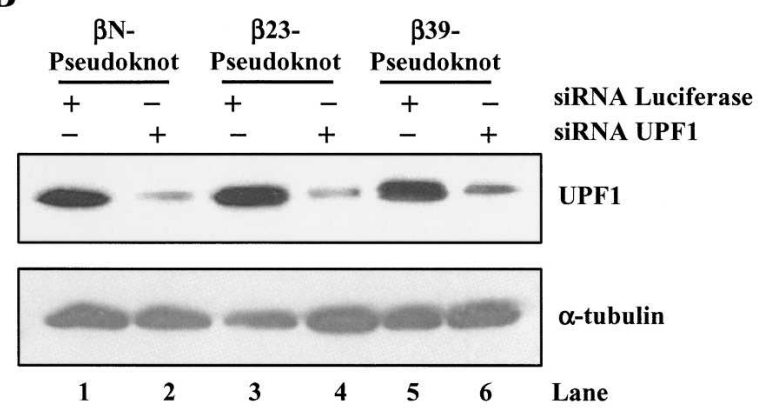

C
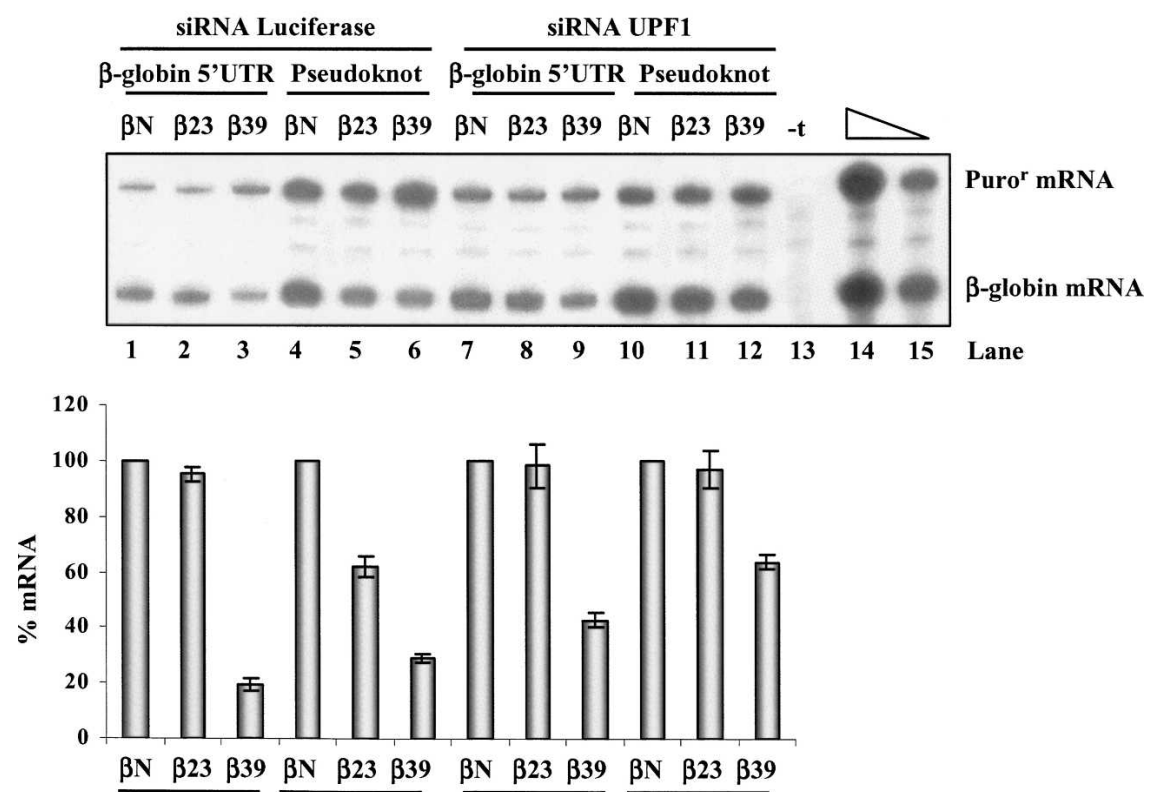

$\beta$-globin 5'UTR Pseudoknot $\beta$-globin 5'UTR Pseudoknot

siRNA Luciferase

SIRNA UPF1

FIGURE 4. (Legend on next page) 
lane 1). Depletion of UPF1 resulted in the expected increase in $\beta 39$ mRNA levels, consistent with the blockade of the NMD pathway. Insertion of the pseudoknot sequence reduced the level of the $\beta 23$ to $64 \%$ of normal (Fig. 4C, cf. lane 5 and lane 4 ) and depletion of UPF1 from the cells restored it to $\beta \mathrm{N}$ mRNA levels (Fig. 4C, cf. lane 11 and lane $10)$. These data demonstrate that insertion of the pseudoknot into the $\beta 23$ mRNA converted this AUG-proximal nonsense-mutated mRNA from NMD resistant to NMD sensitive. These data are consistent with the model that the length of time taken by the ribosome to reach the PTC is a critical parameter in the nature of the termination reaction and the consequent sensitivity to the NMD pathway.

\section{DISCUSSION}

We have previously reported that human $\beta$-globin mRNAs bearing PTCs in the $5^{\prime}$ part of exon 1 fail to be recognized as premature albeit fulfilling the defined criteria for mammalian PTC definition (Romão et al. 2000). We have also reported that this exception to the "50-54 nt boundary rule" is specifically determined by the proximity of the PTC to the initiation AUG codon (Inácio et al. 2004; Silva et al. 2006). The results obtained in the present report point out a number of characteristics of these AUG-proximal nonsensemutated mRNAs that may contribute to these observations. The present data indicate that PABPC1 might participate in the mechanism by which mammalian PTCs are distinguished from natural codons. Indeed, we observe that the artificial tethering of PABPC1 in close proximity to a NMDcompetent PTC represses NMD (Fig. 2). In addition, our present results reveal that the impact of the tethered PABPC1 on NMD is dependent on protein interactions with its C-terminal domain (Fig. 2). This effect most likely reflects interactions with eRF3, which is known to interact with the PABPC1 C-terminal domain in mammalian cells (Uchida et al. 2002). However, other proteins might also make part of this inhibition reaction. This hypothesis is in agreement with previously published results demonstrating that in yeast, tethered poly(A)-binding protein used to mimic a normal $3^{\prime}$ UTR interacts with the termination factor eRF3 and stabilizes nonsense-mutated transcripts (Amrani et al. 2004).

Since PABPC1 proximity to the PTC seems to play a role in NMD inhibition, we further propose that PABPC1 may be protecting mRNAs harboring AUG-proximal PTCs from NMD as a consequence of the inherent nature of the short ORF translation process. In fact, our present findings in combination with prior studies (Inácio et al. 2004; Silva et al. 2006) are in agreement with the hypothesis that in cap-mediated translation, PABPC1 interaction with eIF4G may also enable PABPC1 to travel with the eIF4F/ $43 \mathrm{~S}$ complex as it scans from the cap to the AUG. If a short ORF is translated, by the time the ribosome reaches the stop codon, there may have not been enough time or space to disengage the interactions with all initiation factors, namely with eIF4G, maintaining PABPC1 in the vicinity of AUG. Such a favored location of PABPC1 would then allow its interaction with the terminating ribosome, possibly via eRF3, which, in turn, would impair the interactions between the terminating ribosome and the NMD factors necessary for the surveillance complex assembly. Accordingly, our results show that AUG-proximal nonsense-mutated mRNA becomes NMD sensitive under conditions in which $43 \mathrm{~S}$ scanning is circumvented (Fig. 3) or when the time taken to translate the short ORF is prolonged (Fig. 4).

According to the current view of the mammalian NMD pathway, if the PTC is located at least at $50-54 \mathrm{nt}$ upstream of the last exon-exon junction, then at least one EJC is retained on the mRNA. In these conditions, the interaction between eRF3 and UPF1 at the PTC would enable the interplay between the premature termination complex and the UPF2/UPF3 at the EJC(s), and NMD can be induced. In the context of an AUG-proximal PTC, the inherent nature of an extremely early termination event may be sufficient to maintain PABPC1 favorably located to be able to superimpose its inhibitory effect on NMD activation, despite the presence 
of downstream EJCs. In this way, one can envision a competition mechanism in which eRF3, depending on the position of the PTC, interacts with UPF1 in a way that results in NMD activation, or it preferentially interacts with PABPC1, resulting in a limited association of UPF1 with the mRNP. Consistent with this hypothesis, we observed that NMD-resistant AUG-proximal nonsense-mutated transcripts fail to bind UPF1 as efficiently as those that are NMD sensitive (Fig. 1).

Our findings and the proposed model suggest that PABPC1 plays a role in inhibiting NMD in mammalian systems if it is recruited to an appropriate site on the mRNA. This could be the case for most of the AUGproximal, NMD-resistant PTCs in which the particular features of the mechanism of short ORF translation may account for the maintenance of PABPC1 in the proximity of the PTC. In this regard, a set of mammalian transcripts carrying short upstream (u) ORF(s) has been identified as natural NMD targets (Mendell et al. 2004; Wittmann et al. 2006). However, it should be noted that not all the naturally occurring uORFs in mammalian mRNAs trigger NMD. For example, reporter mRNAs bearing uORF 7 of thrombopoietin mRNA were shown to escape NMD. Yet, an increase in the ORF length induces rapid mRNA decay (Stockklausner et al. 2006). Actually, several of the transcripts that were proposed to be naturally NMD regulated seem to contain at least one uORF holding more than 20 codons (Mendell et al. 2004). Thus, based on our results and considering PTCs that define short ORFs, which are followed by downstream EJC(s), it is possible to hypothesize that there is a certain critical ORF length that determines whether a transcript becomes permissive or resistant to NMD. This critical length, however, may vary among the different transcripts, since the ORF secondary structure might modulate the time taken for the ribosome to translate it.

In yeast, PTC recognition is independent of splicing and EJCs and the proximity of the stop codon to Pablp is considered to be the distinguishing feature between natural and premature stop codons (Amrani et al. 2004, 2006). Consistent with this model, the majority of yeast 3' UTRs are homogeneous in length and aberrant transcripts with exceptionally long 3' UTRs are substrates for NMD (Muhlrad and Parker 1999). In contrast, the requirement for a splicing-dependent signal seems to be a particular feature of mammalian NMD, and it is well established that EJCs play a pivotal role in the mechanism of PTC definition (Behm-Ansmant et al. 2007). In addition, 3' UTRs in mammalian mRNAs are very heterogeneous in length and, thus far, there is no solid evidence of a critical 3' UTR length above which transcripts are targeted for NMD. Therefore, our observation that PABPC1 binding downstream of an NMD-sensitive PTC converts it into NMD resistant does not necessarily indicate that normal stops are defined by their proximity to the $\operatorname{poly}(\mathrm{A})$ tail.
In other words, the inhibitory effect exerted by PABPC1 on NMD activation, when favorably positioned relative to a PTC, does not exclude that in mammals NMD is still mostly EJC dependent. Rather, it indicates that PABPC1 may also play a role in the mechanism of mammalian PTC-definition. This, together with previous studies in S. cerevisiae (Amrani et al. 2004, 2006) and D. melanogaster (Behm-Ansmant et al. 2007) further suggests a conserved role for PABPC1 in recognizing the nature of a stop codon. These observations indicate that certain components of the NMD machinery and pathway have been conserved throughout evolution and suggest that two major determinants for PTC definition may coexist in mammalian cells: the location of the PTC relative to the downstream EJC and the PTC position relative to PABPC1. The involvement of EJC components for NMD in mammalian cells may reflect an additional level of NMD regulation that has been superimposed on the pathway seen in invertebrates.

Besides adding to the understanding of the multiple determinants that rule the mechanism of NMD triggering, our results also touch on another unclear aspect of the NMD pathway. NMD in mammalian cells has been proposed to take place during the so-called pioneer round of translation, while transcripts are still bound by the nuclear CBP80/20 complex rather than by eIF4E (Ishigaki et al. 2001; Lejeune et al. 2002). It was also suggested that CBC might have a role in promoting the interaction of NMD factors with PTC-containing transcripts (Hosoda et al. 2005). While our data do not argue against the requirement of $\mathrm{CBC}$ for NMD activation, we demonstrate that NMD can be elicited under conditions in which translation is independent of CBC-mediated ribosomal recruitment. In fact, our data reveal that recruitment of the ribosome by cap-binding proteins (including the components of the eIF4F complex) is not necessarily required for NMD. These data are consistent with previously published studies showing that cap-independent translation by the encephalomyocarditis virus IRES also supports NMD (Holbrook et al. 2006). Thus our study, along with these previous results, illustrate that translation per se, irrespective of how it is initiated, can mediate the NMD mechanism.

In summary, we show that human $\beta$-globin NMD can be repressed by artificially tethering PABPC1 at close proximity to the PTC. Combining our present findings with data from prior studies (Kozak 2001; Poyry et al. 2004; Silva et al. 2006), we propose a model where the NMD evasion of AUG-proximal nonsense mutated transcripts may reflect a favorable $5^{\prime}$ positioning of $\mathrm{PABPC} 1$, recruited to the vicinity of the initiation codon, during the process of capmediated short ORF translation. This would favor its interaction with the termination complex, which, in turn, would prevent NMD triggering. A detailed understanding of the corresponding biochemical mechanism(s) by which PABPC1 controls ribosomal termination and/or release, as well as 
how it impacts on the association of UPF1 with a prematurely terminating ribosome, are now open to further study.

\section{MATERIALS AND METHODS}

\section{Plasmid constructs}

The wild-type $\beta$-globin gene $(\beta \mathrm{N})$, as well as the human $\beta$-globin variants $\beta 15$ and $\beta 39$ were cloned into the pTRE2pur vector (BD Biosciences) as previously described (Silva et al. 2006). The $\beta$-globin variant $\beta 23$, carrying a nonsense mutation at codon 23 (GTT $\rightarrow$ TAG), was created by site-directed mutagenesis as indicated by the manufacturer (QuikChange Site-Directed Mutagenesis Kit; Stratagene), using mutagenic primers \#1 and \#2 (Table 1) and the construct $\beta \mathrm{N}$ as DNA template. MS2-PABPC1 fusion gene was cloned into the pDEST26-PABPC1 plasmid (IOH13850-pDEST26; RZPD). For that, the DNA fragment encoding the 132-amino acid N-terminal portion of the MS2 coat protein followed by a linker sequence (PRGSH6PN, termed RGSH linker) was amplified by PCR from the plasmid pcDNA3-MS2 (Kong et al. 2003), using primers with SacII and XbaI linkers (Table 1, primers \#3 and \#4) and inserted into SacII/XbaI sites of pDEST26-PABPC1 plasmid, resulting in an in-frame MS2PABPC1 fusion protein-expressing plasmid. The MS2-GFP encoding gene was cloned in a similar way by inserting the HindIII/MfeI fragment from pcDNA3-MS2 (containing the 132amino acid N-terminal portion of MS2 plus RGSH linker) into the HindIII/EcoRI sites of pEGFP-N3 (Clonetech), resulting in an in-frame MS2-GFP fusion protein-expressing plasmid. The pDEST26-MS2-PABPC1delC construct was obtained by deleting the DNA fragment encoding the C-terminal portion of PABPC1.
To accomplish this deletion, the coding sequence of PABPC1, excluding the C-terminal domain (NM 002568, nucleotides 2140 2394, corresponding to C-terminal 85 amino acids), was amplified by PCR from pDEST26-PABPC1 using a pair of primers, one with an AgeI linker (Table 1, primers \#5 and \#6). After HindIII digestion, the PCR DNA product was inserted into HindIII/AgeII sites of pDEST26-MS2-PABPC1. To obtain the $\beta$ N-MS2, $\beta 39$ MS2, $\beta$-globin variants that carry the MS2 binding motif, a 24-bp MS2 binding motif from bacterial phage DNA was inserted in frame at 15 or 44 codons downstream of the nonsense codon (and at the same positions in the normal gene), using the ExSite PCR-Based Mutagenesis Kit (Stratagene) as indicated by the manufacturer, with mutagenic primers $\# 7$ and $\# 8$ or $\# 9$ and \#10, respectively (Table 1 ). The $\beta N$-IRES, $\beta 15$-IRES, and $\beta 39$-IRES gene variants were constructed by replacing the entire native $\beta$-globin $5^{\prime}$ UTR by the CSFV IRES (nucleotides 1-372 from the C/Cs cDNA construct previously described) (Fletcher et al. 2002), maintaining the initiation codon of the $\beta$-globin ORF in the exact position of the viral initiation codon and also replacing the first $14 \beta$-globin codons with those immediately downstream of AUG of the viral CSFV IRES. To obtain this, the ApaI site sequence was inserted into $\beta \mathrm{N}, \beta 15$, and $\beta 39$ constructs between codons 14 and 15 by site-directed mutagenesis with primers \#11, $\# 12$, \#13, and \#14 (Table 1); the viral DNA fragment was amplified by PCR using primers with linkers for ClaI and ApaI (primers $\# 15$ and \#16; Table 1) and inserted into ClaI/ApaI sites of $\beta \mathrm{N}$, $\beta 15$, and $\beta 39$ genes. The $\beta N$-pseudoknot, $\beta 23$-pseudoknot and $\beta 39$-pseudoknot gene variants were constructed by replacing the first 19 codons of a native $\beta$-globin ORF by a 19 -codon sequence resulting in a pseudoknot structure in the mRNA (Kozak 2001), using the ExSite PCR-Based Mutagenesis Kit (Stratagene) as indicated by the manufacturer with mutagenic primers \#17 and

TABLE 1. DNA oligonucleotides used in the current work

\begin{tabular}{ll}
\hline Primer & \multicolumn{1}{c}{ Sequence $\left(5^{\prime} \rightarrow 3^{\prime}\right)$} \\
\hline$\# 1$ & CCCAGGGCCTCACCACCCTATTCATCCACGTTCACC \\
$\# 2$ & GGTGAACGTGGATGAATAGGGTGGTGAGGCCTGGG \\
$\# 3$ & TCCCCGCGGACCATGGCTTCTAACTTTACTCAG \\
$\# 4$ & GCTCTAGAAGAATTGGGATGATGGTGATG \\
$\# 5$ & GTGGAAAATCCAAAGGATTTGG \\
$\# 6$ & ACCGGTCAAAGGTTCCTGACCTCGTAC \\
$\# 7$ & AAACATGAGGATCACCCATGTTTGATGGGCAACCCTAAGGTGAAG \\
$\# 8$ & AACAGCATCAGGAGTGGACAG \\
$\# 10$ & AAACATGAGGATCACCCATGTTTGACCTTTGCCACACTGAGTGAG \\
$\# 11$ & GCCCTTGAGGTTGTCCAGGTG \\
$\# 12$ & GCCGTTACTGCCCTGGGGCCCTGGGGCAAGGTGAAC \\
$\# 13$ & GCCGTTACTGCCCTGGGGCCTGAGGCAAGGTGAAC \\
$\# 14$ & GTTCACCTTGCCCCAGGGCCCCAGGGCAGTAACGGC \\
$\# 15$ & GTTCACCTTGCCtCaGGGCCCCAGGGCAGTAACGGC \\
$\# 16$ & CGGGCCCGCTTGTTTTGTATAATAATTCAA \\
$\# 17$ & GGTGTCTGTTTGAGGTTGC \\
$\# 18$ & ATGGAAGCTTCAACTAGGGGTATCAGTCAGGCTCGGCTGGTACCCCTTGCAAAGCGAGCCGTGGATGAAGTTGGTGGTGAG \\
$\# 19$ & ATGGAAGCTTCAACTAGGGGTATCAGTCAGGCTCGGCTGGTACCCCTTGCAAAGCGAGCCGTGGATGATAGGGTGGTGAG \\
$\# 20$ & GCAATGAAAATAAATGTTTTTAT \\
$\# 21$ & ACATTTGCTTCTGACACAAC \\
$\# 22$ & GAAGGCGTGGGTTGATGTGGAAGA \\
$\# 23$ & GAGCGGGAATTTGAGCGGATGC \\
\hline
\end{tabular}


$\# 18$ (Table 1) and the $\beta \mathrm{N}$ and $\beta 39$ genes as DNA templates, or primers \#17 and \#19 using the $\beta 23$ gene as DNA template.

\section{Cell culture and transfections}

HeLa cells, stably expressing the tet transactivator (HeLa/tTA) (Kong et al. 2003), were grown in Dulbecco's modified Eagle's medium supplemented with $10 \%$ fetal bovine serum. Transient transfections were performed using Lipofectamine 2000 Transfection Reagent (Invitrogen), following the manufacturer's instructions, in $35-\mathrm{mm}$ plates using $250 \mathrm{ng}$ of the test construct DNA and 1750 ng of pEGFP vector (BD Biosciences) to control for transfection efficiency. For the tethering assays, $1750 \mathrm{ng}$ of pDEST26-PABPC1, pDEST26-MS2-PABPC1, pDEST26-MS2PABPC1delC, or pE-MS2-GFP plasmids were cotransfected with $250 \mathrm{ng}$ of the test construct DNA. For CSFV IRES-mediated translation assays $1750 \mathrm{ng}$ of pCMVSport3PTB1 or pEGFP plasmids were cotransfected with $250 \mathrm{ng}$ of the test construct DNA into HeLa cells. To stimulate the IRES activity in the HeLa cells, the plasmids encoding the $\beta \mathrm{N}, \beta 15$, and $\beta 39$ mRNAs with CSFV IRES 5' UTRs were each cotransfected with a plasmid encoding the pyrimidine tract-binding protein (PTB) (Anwar et al. 2000; Gosert et al. 2000). PTB coexpression enhanced the destabilization of the CSFV IRES $\beta 39$ mRNA, consistent with the translationdependence of NMD and had no effect on the native (i.e., with the native $5^{\prime}$ UTR) $\beta \mathrm{N}, \beta 15$, and $\beta 39$ transcripts (data not shown). Cells were harvested after a 20 -h transcription pulse. Stable transfections were performed as described for transient transfections, using $2 \mu \mathrm{g}$ of each $\beta$-globin encoded plasmid. Stable transfected cells pools were selected using $1.5 \mu \mathrm{g} / \mathrm{mL}$ puromycin (Sigma).

\section{Transient transfection of siRNAs}

Transfections of cells with siRNAs were carried out using Lipofectamine 2000 reagent (Invitrogen) according to the manufacturer's instructions in 35-mm plates using 100 pmol of siRNA oligonucleotides and $4 \mu \mathrm{L}$ of transfection reagent. Twenty-four hours later, cells were transfected with an additional 50 pmol of siRNAs along with $250 \mathrm{ng}$ of the test construct DNA and $1000 \mathrm{ng}$ of pEGFP vector as carrier. After an additional 24-h incubation the cells were harvested for analysis of RNA and protein expression. The siRNA oligonucleotides used for transfections (Luciferase [AA-CGUACGCGGAAUACUUCGA] and hUPF1 [AA-GAUGCA GUUCCGCUCCAUU]) were purchased as annealed, ready-to-use duplexes from Dharmacon.

\section{RNA isolation}

Total RNA from transfected cells was prepared using the RNeasy mini kit (Qiagen) following the manufacturer's indications. RNA samples were treated with RNase-free DNase I (Ambion) and purified by phenol:chloroform extraction. Before further analyses, mRNA samples were assessed by RT-PCR for utilization of cryptic splicing pathway(s) that might circumvent the premature termination codon. From all transcript species a single full-length product was amplified (data not shown), demonstrating that the studied nonsense transcripts present a normal splicing pattern.

\section{Ribonuclease protection assays (RPA)}

Probes used were generated by in vitro transcription, using a Maxiscript SP6 or T7 kit (Ambion), under conditions recom- mended by the manufacturer. The human $\beta$-globin exon 3 and Puro $^{\mathrm{r}}$ probes were previously described (Inácio et al. 2004; Silva et al. 2006). Samples were processed as previously described (Inácio et al. 2004).

\section{Semiquantitative RT-PCR}

Pre-IP and coimmunoprecipitated RNA $(5 \mu \mathrm{L})$ were reversetranscribed (RT) with Superscript II (Invitrogen) according to the manufacturer's standard protocol and using 2 pmol of reverse primer for each mRNA target (primers \#20 and \#22 for $\beta$-globin and RNA polymerase II [Pol II] transcripts, respectively; Table 1), in a final volume of $20 \mu \mathrm{L}$. The PCR reactions for $\beta$-globin and Pol II were performed in parallel at similar conditions: $5 \mu \mathrm{L}$ of the RT product was amplified in a $20-\mu \mathrm{L}$ reaction volume using $0.2 \mathrm{mM}$ dNTPs, $1.5 \mathrm{mM} \mathrm{MgCl}_{2}, 10 \mathrm{pmol}$ of each primer (primers $\# 20$ and \#21 for $\beta$-globin and primers \#22 and \#23 for RNA polII, respectively; Table 1), $0.75 \mathrm{U}$ of AmpliTaq (Promega), and $1 \times$ PCR buffer (Promega). Thermocycler conditions were $95^{\circ} \mathrm{C}$ for $3 \mathrm{~min}$ followed by 20 cycles of $95^{\circ} \mathrm{C}$ for $30 \mathrm{sec}, 54^{\circ} \mathrm{C}$ for $40 \mathrm{sec}$, and $72^{\circ} \mathrm{C}$ for $40 \mathrm{sec}$ followed by a final extension of $72^{\circ} \mathrm{C}$ for $10 \mathrm{~min}$. Ten-microliter aliquots from each RT-PCR sample were analyzed by electrophoresis on $1 \%$ agarose gels. All PCR reactions were performed in duplicate. For densitometric analysis ethidiumbromide stained gels were digitalized and analyzed using ImageJ software $(\mathrm{NIH})$.

\section{Immunoprecipitation (IP)}

Approximately $1 \times 10^{6} \mathrm{HeLa}$ cells (pool of selected cells), stably transfected with $\beta \mathrm{N}, \beta 15$, or $\beta 39$ constructs, were seeded in $60-\mathrm{mm}$ dishes and assayed $24 \mathrm{~h}$ later. Cells were washed in cold PBS and lysed on ice in $275 \mu \mathrm{L}$ of lysis buffer $(50 \mathrm{mM}$ Tris- $\mathrm{HCl}$ at $\mathrm{pH} 7.5,0.5 \%$ [v/v] Nonidet P-40, $100 \mathrm{mM} \mathrm{NaCl}, 10 \mathrm{mM} \mathrm{MgCl}$, $100 \mathrm{U}$ of RNase inhibitor per milliliter [Invitrogene] and protease inhibitor mixture [Sigma]). Total lysates were cleared by centrifugation at $2500 \mathrm{~g}$ for $5 \mathrm{~min}$. A $25 \mu \mathrm{L}$ aliquot of total lysate (PreIP) was used for RNA and protein analysis (a $12.5 \mu \mathrm{L}$ aliquot was used for RNA extraction as described above and resuspended in $10 \mu \mathrm{L} \mathrm{H}_{2} \mathrm{O}$, prior to semiquantitative RT-PCR analysis; $25 \mu \mathrm{L}$ of $2 \times$ SDS loading buffer were added to the other $12.5 \mu \mathrm{L}$ aliquot for Western blot analysis). The lysate was incubated for $3 \mathrm{~h}$ at $4^{\circ} \mathrm{C}$ with goat polyclonal anti-hUPF1 (Bethyl Labs), rabbit polyclonal anti-hUPF2 (a gift from J. Lykke-Andersen, University of Colorado), or goat polyclonal anti-hUPF3 (Santa Cruz), all at a 1:100 dilution. Protein G-agarose beads (Roche) were then added and samples were incubated for $3 \mathrm{~h}$ at $4^{\circ} \mathrm{C}$. Precipitated complexes were washed three times with excess wash buffer $(20$ mM HEPES at $\mathrm{pH} 7.9,150 \mathrm{mM} \mathrm{NaCl}, 0.05 \%$ Triton X-100, $100 \mathrm{U}$ of RNase inhibitor per milliliter). After the final wash, the precipitate was split into two aliquots used, respectively, for RNA and protein analysis. For RNA analysis, the supernatant was discarded and $400 \mu \mathrm{L}$ of IP RNA-elution buffer $(0.1 \mathrm{M}$ Tris- $\mathrm{HCl}$ at $\mathrm{pH} 7.5$, $12.5 \mathrm{mM}$ EDTA, $0.15 \mathrm{M} \mathrm{NaCl}, 1 \% \mathrm{SDS}$ ) were added to the protein G-Agarose-RNP complex pellet and the complex was disrupted by boiling for $3 \mathrm{~min}$. RNA was then phenol extracted, ethanol precipitated, and resuspended in $10 \mu \mathrm{L}$ of $\mathrm{H}_{2} \mathrm{O}$, prior to semiquantitative RT-PCR analysis. For protein analysis, the supernatant was discarded and $20 \mu \mathrm{L}$ of $2 \times$ SDS loading buffer were added to the beads and boiled for $5 \mathrm{~min}$. Total lysates and precipitates were then analyzed by Western blot. 


\section{SDS-PAGE and Western blotting}

Protein lysates were resolved, according to standard protocols, in $10 \%$ SDS-PAGE and transferred to PVDF membranes (Bio-Rad). Membranes were probed using mouse monoclonal anti- $\alpha$-tubulin (Sigma) at 1:10,000 dilution, goat polyclonal anti-PABPC1 Nterminal domain (Santa Cruz) at 1:100 dilution, goat polyclonal anti-hUPF1 (Bethyl Labs) at 1:500 dilution, rabbit polyclonal antihUPF2 at 1:1000 dilution, or goat polyclonal anti-hUPF3 (Santa Cruz) at 1:100 dilution. Detection was carried out using secondary peroxidase-conjugated anti-mouse IgG (Bio-Rad), anti-rabbit IgG (Bio-Rad) or anti-goat IgG (Sigma) antibodies followed by chemiluminescence.

\section{Statistical analysis}

When appropriate, statistical analysis of the data was performed applying the Student's $t$-test.

\section{ACKNOWLEDGMENTS}

We thank R.J. Jackson (University of Cambridge, Cambridge, UK) for providing a plasmid carrying the CSFV IRES, J. LykkeAndersen (University of Colorado, Boulder, CO) for providing the UPF2 antibody, A. Moreira (Instituto de Biologia Molecular e Celular, Universidade do Porto, Porto, Portugal) for providing the plasmid pCMVSport3PTB1 (from C.W.J. Smith; University of Cambridge, Cambridge, UK), P. Matos for technical assistance, S. Pedro for GeneScan analysis, and J. Lavinha for comments on the manuscript. This work was partially supported by Fundação para a Ciência e a Tecnologia (POCTI/SAU-MMO/57573/2004 and Programa de Financiamento Plurianual do CIGMH). A.L.S. and A.I. were supported by Fellowships from Fundação para a Ciência e a Tecnologia. S.A.L. is supported by NIH MERIT Grant R37-HL65449 and PO1 CA72765.

Received September 5, 2007; accepted November 21, 2007.

\section{REFERENCES}

Amrani, N., Ganesan, R., Kervestin, S., Mangus, D.A., Ghosh, S., and Jacobson, A. 2004. A faux 3'-UTR promotes aberrant termination and triggers nonsense-mediated mRNA decay. Nature 432: 112118.

Amrani, N., Sachs, M.S., and Jacobson, A. 2006. Early nonsense: mRNA decay solves a translational problem. Nat. Rev. Mol. Cell Biol. 7: 415-425.

Anwar, A., Ali, N., Tanveer, R., and Siddiqui, A. 2000. Demonstration of functional requirement of polypyrimidine tract-binding protein by SELEX RNA during hepatitis $\mathrm{C}$ virus internal ribosome entry site-mediated translation initiation. J. Biol. Chem. 275: 3423134235.

Behm-Ansmant, I., Gatfield, D., Rehwinkel, J., Hilgers, V., and Izaurralde, E. 2007. A conserved role for cytoplasmic poly(A)binding protein 1 (PABPC1) in nonsense-mediated mRNA decay. EMBO J. 26: 1591-1601.

Chang, Y.F., Imam, J.S., and Wilkinson, M.F. 2007. The nonsensemediated decay RNA surveillance pathway. Annu. Rev. Biochem. 76: $51-74$.

Conti, E. and Izaurralde, E. 2005. Nonsense-mediated mRNA decay: Molecular insights and mechanistic variations across species. Curr. Opin. Cell Biol. 17: 316-325.
Fletcher, S.P., Ali, I.K., Kaminski, A., Digard, P., and Jackson, R.J. 2002. The influence of viral coding sequences on pestivirus IRES activity reveals further parallels with translation initiation in prokaryotes. RNA 8: 1558-1571.

Gosert, R., Chang, K.H., Rijnbrand, R., Yi, M., Sangar, D.V., and Lemon, S.M. 2000. Transient expression of cellular polypyrimidine-tract binding protein stimulates cap-independent translation directed by both picornaviral and flaviviral internal ribosome entry sites in vivo. Mol. Cell. Biol. 20: 1583-1595.

Holbrook, J.A., Neu-Yilik, G., Gehring, N.H., Kulozik, A.E., and Hentze, M.W. 2006. Internal ribosome entry sequence-mediated translation initiation triggers nonsense-mediated decay. EMBO Rep. 7: 722-726.

Hoshino, S., Imai, M., Kobayashi, T., Uchida, N., and Katada, T. 1999. The eukaryotic polypeptide chain releasing factor (eRF3/GSPT) carrying the translation termination signal to the $3^{\prime}$-Poly(A) tail of mRNA. Direct association of erf3/GSPT with polyadenylatebinding protein. J. Biol. Chem. 274: 16677-16680.

Hosoda, N., Kim, Y.K., Lejeune, F., and Maquat, L.E. 2005. CBP80 promotes interaction of Upf1 with Upf2 during nonsense-mediated mRNA decay in mammalian cells. Nat. Struct. Mol. Biol. 12: 893-901.

Inácio, A., Silva, A.L., Pinto, J., Ji, X., Morgado, A., Almeida, F., Faustino, P., Lavinha, J., Liebhaber, S.A., and Romão, L. 2004. Nonsense mutations in close proximity to the initiation codon fail to trigger full nonsense-mediated mRNA decay. J. Biol. Chem. 279: 32170-32180.

Ishigaki, Y., Li, X., Serin, G., and Maquat, L.E. 2001. Evidence for a pioneer round of mRNA translation: mRNAs subject to nonsensemediated decay in mammalian cells are bound by CBP80 and CBP20. Cell 106: 607-617.

Jackson, R.J. 2005. Alternative mechanisms of initiating translation of mammalian mRNAs. Biochem. Soc. Trans. 33: 1231-1241.

Kashima, I., Yamashita, A., Izumi, N., Kataoka, N., Morishita, R., Hoshino, S., Ohno, M., Dreyfuss, G., and Ohno, S. 2006. Binding of a novel SMG-1-Upf1-eRF1-eRF3 complex (SURF) to the exon junction complex triggers Upf1 phosphorylation and nonsensemediated mRNA decay. Genes \& Dev. 20: 355-367.

Kong, J., Ji, X., and Liebhaber, S.A. 2003. The KH-domain protein $\alpha \mathrm{CP}$ has a direct role in mRNA stabilization independent of its cognate binding site. Mol. Cell. Biol. 23: 1125-1134.

Kozak, M. 1987. Effects of intercistronic length on the efficiency of reinitiation by eucaryotic ribosomes. Mol. Cell. Biol. 7: 3438-3445.

Kozak, M. 2001. Constraints on reinitiation of translation in mammals. Nucleic Acids Res. 29: 5226-5232.

Le Hir, H., Gatfield, D., Izaurralde, E., and Moore, M.J. 2001. The exon-exon junction complex provides a binding platform for factors involved in mRNA export and nonsense-mediated mRNA decay. EMBO J. 20: 4987-4997.

Lejeune, F., Ishigaki, Y., Li, X., and Maquat, L.E. 2002. The exon junction complex is detected on CBP80-bound but not eIF4E-bound mRNA in mammalian cells: Dynamics of mRNP remodeling. EMBO J. 21: 3536-3545.

Mendell, J.T., Sharifi, N.A., Meyers, J.L., Martinez-Murillo, F., and Dietz, H.C. 2004. Nonsense surveillance regulates expression of diverse classes of mammalian transcripts and mutes genomic noise. Nat. Genet. 36: 1073-1078.

Muhlrad, D. and Parker, R. 1999. Aberrant mRNAs with extended 3' UTRs are substrates for rapid degradation by mRNA surveillance. RNA 5: 1299-1307.

Pestova, T.V., Shatsky, I.N., Fletcher, S.P., Jackson, R.J., and Hellen, C.U. 1998. A prokaryotic-like mode of cytoplasmic eukaryotic ribosome binding to the initiation codon during internal translation initiation of hepatitis $\mathrm{C}$ and classical swine fever virus RNAs. Genes \& Dev. 12: 67-83.

Poyry, T.A., Kaminski, A., and Jackson, R.J. 2004. What determines whether mammalian ribosomes resume scanning after translation of a short upstream open reading frame? Genes \& Dev. 18: 62-75. 


\section{Silva et al.}

Reynolds, J.E., Kaminski, A., Carroll, A.R., Clarke, B.E., Rowlands, D.J., and Jackson, R.J. 1996. Internal initiation of translation of hepatitis C virus RNA: The ribosome entry site is at the authentic initiation codon. RNA 2: 867-878.

Rijnbrand, R., van der Straaten, T., van Rijn, P.A., Spaan, W.J., and Bredenbeek, P.J. 1997. Internal entry of ribosomes is directed by the $5^{\prime}$ noncoding region of classical swine fever virus and is dependent on the presence of an RNA pseudoknot upstream of the initiation codon. J. Virol. 71: 451-457.

Romão, L., Inácio, A., Santos, S., Ávila, M., Faustino, P., Pacheco, P., and Lavinha, J. 2000. Nonsense mutations in the human $\beta$-globin gene lead to unexpected levels of cytoplasmic mRNA accumulation. Blood 96: 2895-2901.

Silva, A.L., Pereira, F.J., Morgado, A., Kong, J., Martins, R., Faustino, P., Liebhaber, S.A., and Romão, L. 2006. The canonical UPF1-dependent nonsense-mediated mRNA decay is inhibited in transcripts carrying a short open reading frame independent of sequence context. RNA 12: 2160-2170.

Stockklausner, C., Breit, S., Neu-Yilik, G., Echner, N., Hentze, M.W., Kulozik, A.E., and Gehring, N.H. 2006. The uORF-containing thrombopoietin mRNA escapes nonsense-mediated decay (NMD). Nucleic Acids Res. 34: 2355-2363. doi: 10.1093/nar/ gkl277.

Uchida, N., Hoshino, S., Imataka, H., Sonenberg, N., and Katada, T. 2002. A novel role of the mammalian GSPT/eRF3 associating with poly(A)-binding protein in Cap/Poly(A)-dependent translation. J. Biol. Chem. 277: 50286-50292.

Wells, S.E., Hillner, P.E., Vale, R.D., and Sachs, A.B. 1998. Circularization of mRNA by eukaryotic translation initiation factors. Mol. Cell 2: 135-140.

Wittmann, J., Hol, E.M., and Jack, H.M. 2006. hUPF2 silencing identifies physiologic substrates of mammalian nonsense-mediated mRNA decay. Mol. Cell. Biol. 26: 1272-1287. 

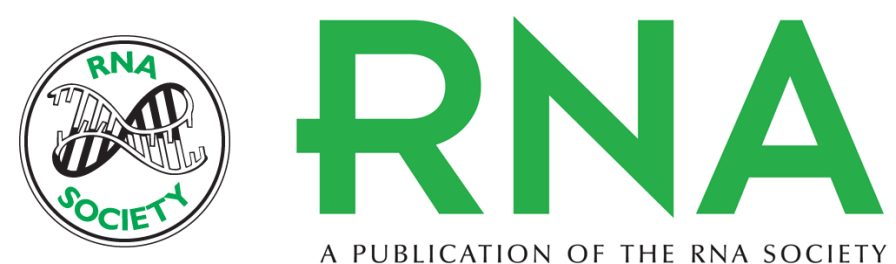

A PUBLICATION OF THE RNA SOCIETY

\section{Proximity of the poly(A)-binding protein to a premature termination codon inhibits mammalian nonsense-mediated mRNA decay}

Ana Luísa Silva, Patrícia Ribeiro, Ângela Inácio, et al.

RNA 2008 14: 563-576

References This article cites 32 articles, 19 of which can be accessed free at:

http://rnajournal.cshlp.org/content/14/3/563.full.html\#ref-list-1

License

Email Alerting Receive free email alerts when new articles cite this article - sign up in the box at the Service top right corner of the article or click here. 